\title{
Targeting Autism in Libraries: A Comprehensive and Collaborative Training Program for Librarians
}

Ruth V. Small, Syracuse University, USA

Suzanne Schriar, Illinois State Library, USA

Mary Pelich Kelly, The Autism Program of Illinois, USA

\begin{abstract}
This article describes the Targeting Autism program, funded by multiple grants from the Institute of Museum \& Library Services (IMLS). This program was created to provide free training to the librarians of the State of Illinois on providing quality services and programs to patrons with autism. The State Library of Illinois leads the project, in partnership with Dominican University and Syracuse University and in collaboration with dozens of autismrelated organizations. The Targeting Autism program has included a variety of educational opportunities-in-person annual forums, group workshops, follow-up individualized coaching, Webinars, blogs, and an online self-paced, in-depth training program for individuals or groups through Project ENABLE (Expanding Non-discriminatory Access to Librarians Everywhere) to librarians in Illinois and beyond. The program is a model for the development of similar programs both nationally and internationally.
\end{abstract}

Keywords: autism; libraries; training

Publication Type: special section publication

\section{Introduction}

$\mathrm{T}$ he 2010 U.S. Census reported that more than 56 million people (close to 20\% of the population) have a disability (Brault, 2012, p. 4). One in six children in the U.S. has a developmental disability (e.g., attention deficit/hyperactivity disorder, autism, intellectual disability) (Centers for Disease Control and Prevention [CDC], 2018), constituting large, neurodiverse populations within our schools and communities.

Library and information science research indicates that many librarians lack the appropriate knowledge, skills, and attitudes for providing effective library and information programs, services, and resources for people with disabilities (e.g., Nelson, 1996; Small, Snyder \& Parker, 2009) even though research also indicates that many librarians want and are actively seeking training in this area (Small, Myhill, and Herring-Harrington, 2015). In response to this research, several efforts have been made by a variety of individuals and organizations to provide disabilities training to librarians.

This article tells the story of one such effort, a comprehensive program focused on library services to people with autism in the State of Illinois. Aptly named Targeting Autism, this

The International Journal of Information, Diversity, \& Inclusion, 3(4), 2019

ISSN 2574-3430, jps.library.utoronto.ca/index.php/ijidi/index

DOI: $10.33137 /$ ijidi.v3i4.32998 
program has had an impact that goes far beyond its borders, influencing library programs and services across the U.S. and serving as a model to other such efforts both nationally and internationally.

\section{Background}

The Targeting Autism initiative was conceived by Suzanne Schriar, Associate Director, Illinois State Library, in 2013 to address the need for accommodations and relevant library programming that would serve to increase library engagement among autistic residents and their families. The life-enhancing mission of libraries combined with the large incidence of autism in the United States challenges libraries to adapt programming and library services to meet the needs of our increasingly neurodiverse world. The importance of ensuring that all libraries become inclusive of individuals whose disabilities are not physically visible is increasing as the numbers of autistic individuals continue to rise. In 2014, according to the CDC (2018), the incidence is reported as 1 in 59 births. Still, many more people are impacted when family members and those with autism and no formal diagnosis are considered.

During 2013, an online search was conducted at the Illinois State Library to discover the extent to which libraries throughout the nation were actively engaged in accommodating and providing programming that specifically addresses the needs of residents impacted by autism. The noteworthy, model initiatives were few and they are identified below:

- Libraries and Autism: We're Connected - a model New Jersey program that began in 2008 through a collaboration between Scotch Plains Public Library and Fanwood Public Library. The program was designed to help patrons with autism have a more comfortable and positive library experience.

- Project ENABLE (Expanding Non-discriminatory Access By Librarians Everywhere) - an IMLS funded project which began at Syracuse University in 2011 as an initiative to provide in-depth disabilities training to school librarians. Project ENABLE has grown and is now a free, foundational training site, designed for all types of librarians, worldwide, to help them gain the knowledge and skills needed to create inclusive and accessible libraries that meet the needs of all people.

- $\quad$ Project PALS - an IMLS funded project which began at Florida State University in 2013 as an education program to improve information services for patrons with autism living in the Florida Panhandle. PALS has expanded nationally, providing access to a free selfpaced autism training course.

- SNAILS (Special Needs and Inclusive Library Services) - a networking group made up of professionals from the Chicago-area public libraries. Since 2013, through collaboration and training, SNAILS has supported the efforts of over 40 public libraries in providing specialized services and programs to children and teens with disabilities.

In addition to the online search, the Illinois State Library conducted a survey to determine if Illinois librarians saw a need for training about autism and how to better serve autistic individuals and family members. Of 202 respondents to the survey, only $55(27.2 \%)$ reported that their libraries provided any special services to patrons with autism. The survey results also pointed to an interest in convening a forum for furthering the discussion on the need for better

The International Journal of Information, Diversity, \& Inclusion, 3(4), 2019

ISSN 2574-3430, jps.library.utoronto.ca/index.php/ijidi/index

DOI: $10.33137 /$ ijidi.v3i4.32998 
training and ways that the library community could foster additional collaboration and support.

\section{Getting Started}

Pursuant to the research results, the Illinois State Library applied for and received an IMLS National Leadership Grant, Targeting Autism: A National Forum on Serving Library Patrons on the Spectrum. In 2015 and 2016, two informational face-to-face forums were convened in Springfield, IL that were designed to: (a) help participants gain a basic understanding of autism; (b) discuss the role of libraries in serving autistic individuals and family members; (c) share expertise and resources; and (d) initiate multi-stakeholder collaboration in the design of programming and services to increase the value and use of libraries with the autism community. Although focused on Illinois librarians, some librarians from other states traveled to Springfield to attend.

Librarians, service providers, teachers, and self-advocates participated in the forums. Presentations by numerous authors and subject experts informed the conversations. Librarians learned how to conduct needs assessments in their communities. They gained a deeper understanding of the importance of partnering with community stakeholders and disabilities advocates to engage residents impacted by autism and ensure accessibility and optimal accommodations.

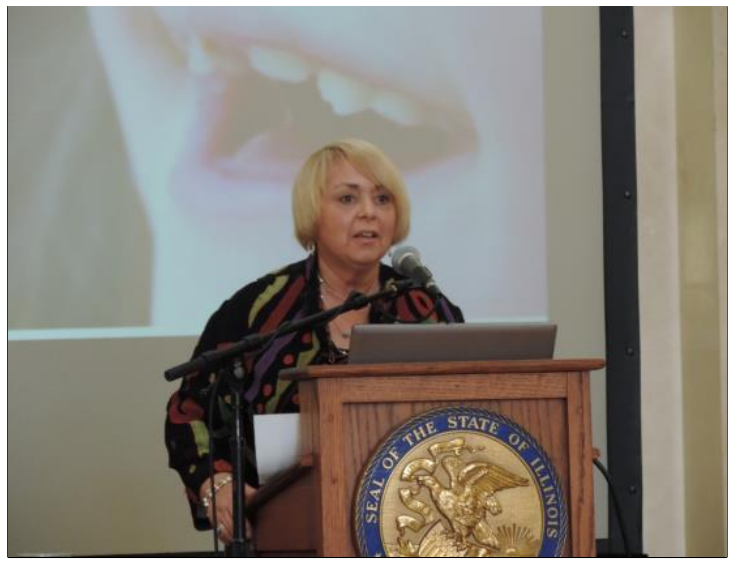

Figure 1. Dr. Ruth Small, Professor and Director of Project ENABLE at Syracuse University, shares information about Project ENABLE to the 2015 Targeting Autism forum about online training for librarians. [Reproduced by permission]

In addition, librarians learned that there is a need for more of the following:

- reliable information resources for parents;

- $\quad$ support groups;

- employment services;

- $\quad$ proliferation of inclusive spaces;

The International Journal of Information, Diversity, \& Inclusion, 3(4), 2019

ISSN 2574-3430, jps.library.utoronto.ca/index.php/ijidi/index

DOI: $10.33137 /$ ijidi.v3i4.32998 
- more intervention in schools;

- job fairs and interview skills mentoring;

- teen social groups;

- collaboration between schools and libraries;

- doctors referring families to libraries for information and to guide them to resources;

- intern programs at libraries for autistic residents;

- assistive technology training in libraries;

- more welcoming, sensory friendly, calming libraries;

- more quiet spaces and noise cancelling headphone available in libraries;

- more visible supports in libraries; and

- $\quad$ more use of social stories.

As one Illinois public librarian stated, "By raising my awareness, the program has created another advocate for our autistic patrons. Building a better library [autism] collection to include books for kids and parents, creating quiet spaces/sensory spaces has improved my library services."

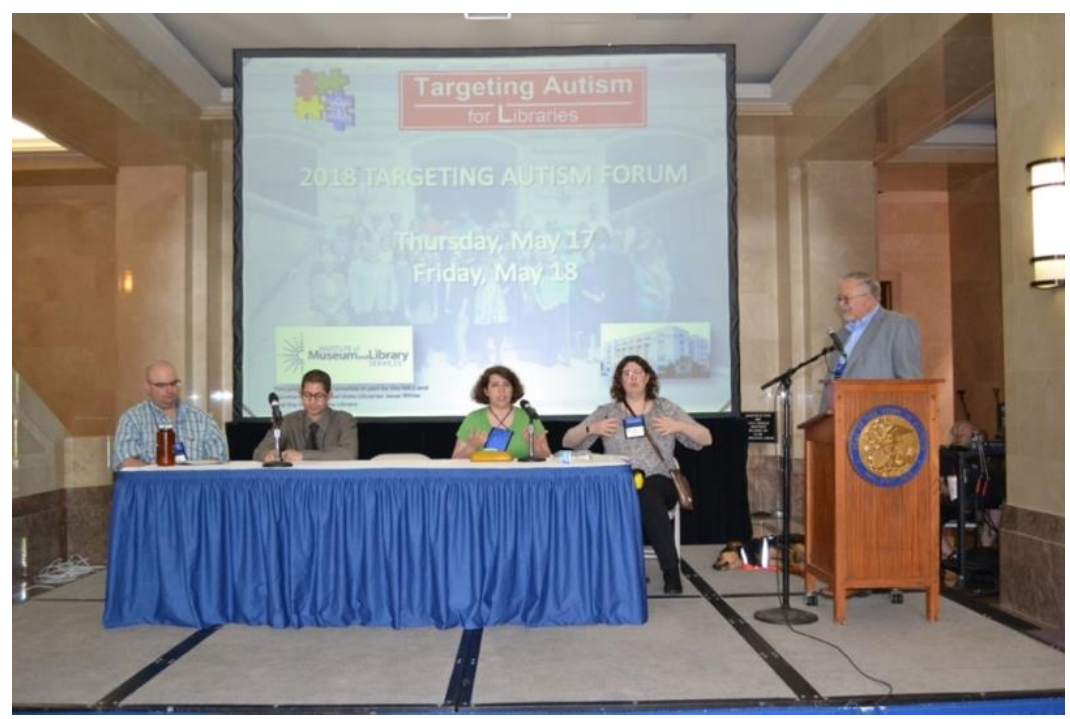

Figure 2. A panel of autistic librarians shared their experiences at the 2018 Targeting Autism forum. Left to right: Charlie Remy, U. of Chattanooga (TN); Gyasi Burks-Abbott, LEND (MA); Stephanie Diorio, Hoboken Public Library (NJ); Erin Miller, Cudahy Family Library (WI); Russ Bonanno, CEO, LifeDesigns (IN), panel moderator. [Reproduced by permission]

The International Journal of Information, Diversity, \& Inclusion, 3(4), 2019

ISSN 2574-3430, jps.library.utoronto.ca/index.php/ijidi/index

DOI: $10.33137 /$ ijidi.v3i4.32998 


\section{Next Steps}

The success of the Targeting Autism forums led to a second IMLS grant to provide a series of face-to-face autism training workshops, library site visits, and consultations throughout Illinois. In addition, webinars, annual forums, and the creation of a comprehensive online autism training module with Syracuse University's Project ENABLE training website would increase the size and scope of the project. To achieve these ambitious objectives, the Illinois State Library partnered with Dominican University and Syracuse University on an IMLS Laura Bush 21st Century Librarian grant project titled, Targeting Autism: A Comprehensive Training and Education Program for Librarians.

Annual forums continued to be held in Springfield, IL in 2017 and 2018. Because much of the data pointed to a lack of independence and a high rate of unemployment of young adults with autism (Sparrow, 2018), the forums included a greater focus on the population of autistic youth who have aged out of legally mandated support services. Autism self-advocates, such as Michael John Carley, Kerry Magro and Morénike Giwa Onaiwu shared their personal challenges and advice for living a satisfying and independent life. Both years included a panel of autistic librarians sharing personal stories about their work experience and their views regarding selfdisclosure to their boss and/or colleagues. The panel at the 2018 forum shared their thoughts about how libraries can improve the hiring process for people with autism.

A combined total of 320 librarians attended all four forums from 2015 to 2019. The impact of these forums is evidenced by the following comment from a forum attendee, "I drive from Lexington, Kentucky because of how crucial this information \& professional development is. . . . I've taken this knowledge and applied it to employee sensitivity training."

\section{Partnering with Dominican University}

Over a two-year period beginning in 2017, the Targeting Autism project in partnership with Dominican University conducted a series of five intensive two-day autism workshops for libraries throughout Illinois. The workshop content focused on understanding the general characteristics of autism, including behavioral, communication, and issues with social functioning. In addition, the concept of Universal Design and the responsibility of librarians to comply with the Americans with Disabilities Act (ADA) for non-physical disabilities were also addressed. Best library practices were shared for adapting physical spaces, providing sensoryfriendly programming, and meeting the resource needs for families impacted by autism. These in-person sessions also provided an opportunity for librarians to network and encouraged communication to continue beyond the workshop and through the Targeting Autism discussion listserv and online social media sites. The overall goal was to ensure that libraries implement changes that offer the type of environment, programming and resources needed to increase engagement of their growing neurodiverse patron population.

The 47 librarians who attended these sessions shared their newly gained knowledge with their colleagues and committed to making at least one change to a program, service, or to their facility that would make their library more welcoming and engaging for their autistic patrons. Follow-up library visits and consultations were provided to ensure that the education spread beyond the participants who attended the workshops and to ensure that training resulted in positive outcomes.

The International Journal of Information, Diversity, \& Inclusion, 3(4), 2019

ISSN 2574-3430, jps.library.utoronto.ca/index.php/ijidi/index

DOI: $10.33137 /$ ijidi.v3i4.32998 


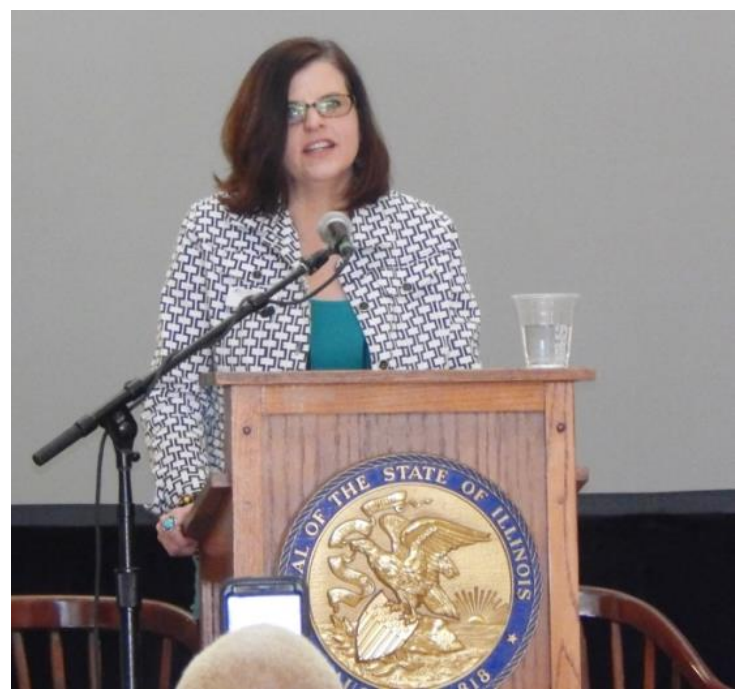

Figure 3. Mary Pelich Kelly, Coordinator, The Autism Program of Illinois and trainer for the Targeting Autism workshops, delivers a talk, “A Mother's Journey: Raising a Son with Autism," to attendees at the 2016 Targeting Autism forum.

The train-the-trainer workshops have borne remarkable results. Librarians trained during these workshops have developed lasting collaborations through sharing ideas and resources to improve accessibility and services for neurodiverse patrons. All of the libraries that have received follow-up consultations or site visits have begun or accomplished at least one actionable goal that makes their libraries more inclusive.

Libraries throughout the Chicago area have made changes to their facilities by creating quiet rooms or low-sensory spaces for individuals to relax and reset. Many now provide accessible accommodations such as noise canceling headphones and fidgets for use in the library and during sensory-friendly programming. Several libraries also provide autism resources and collections for the community and one has created "Calming Kits" that are frequently borrowed by teachers, families, and community groups.

Two public libraries accomplished a great deal toward ensuring inclusivity, culminating in presenting their best-practices to the 2018 Targeting Autism forum attendees. One public library located in northern Illinois has provided autism training for their board of directors and staff on inclusive best-practices in the library. Librarians created their own "autism-friendly" logo, which is displayed on the front doors of their library and on library materials and throughout the library. They also created an autism resource center with rotating collections. In addition, partnerships were formed with several nearby libraries to offer weekly sensory programming for families. To date, this library has created and offered several calm-down spaces for use by patrons of all ages and abilities.

The director of a rural public library in Illinois has developed collaborative relationships with an autism parent group, local schools, community organizations, and businesses in two counties in southeastern Illinois to find ways to serve the unmet needs of autistic youth and families in the region. Here, the library acts as the conduit for outreach and inclusive programming that takes place throughout the region, providing services that would otherwise be unavailable.

The International Journal of Information, Diversity, \& Inclusion, 3(4), 2019

ISSN 2574-3430, jps.library.utoronto.ca/index.php/ijidi/index

DOI: $10.33137 /$ ijidi.v3i4.32998 
Finally, a public library in southern Illinois employs one individual with autism who meticulously cleans the library each week. In addition, following the training workshop in 2018, library staff created a social story for patrons with autism and other developmental disabilities. Utilizing universal design principles, it is currently being expanded into a variety of social stories designed to meet the needs of autistic patrons with varying abilities and to provide a valuable resource to assist their many Japanese speaking patrons with using the library. Staff has also begun a monthly sensory story hour, which is attended by 60 to 75 children from throughout the rural southern Illinois region. Their successful inclusive initiatives were featured in a poster session at the 2019 Targeting Autism Forum. A comment by an Illinois public librarian sums up reaction to these workshops. "Before the Train-the-Trainer workshop, I knew next to nothing about serving patrons with autism. I am still learning, but I am so glad that Targeting Autism started me on the path to better serving ALL of our library patrons."

\section{Partnering with Syracuse University}

Syracuse University's Project ENABLE (Expanding Non-discriminatory Access By Librarians Everywhere), a recipient of four successive awards from the IMLS Laura Bush $21^{\text {st }}$ Century Librarian grants program beginning in 2010 (including one in partnership with Targeting Autism), launched a free and comprehensive, multimedia self-paced online disabilities training program for librarians in 2012 (https://projectenable.syr.edu). Project ENABLE's approach to disabilities training takes a more general perspective through five learning modules covering broad topics such as disabilities awareness, laws and policies, assistive technologies, and creating inclusive and accessible libraries and library programs and services for people with disabilities. Free registration for the Project ENABLE training is required for the purpose of collecting more detailed usage statistics.

In addition to text, each module contains photos, videos, interactive games, activities, thinking challenges, active links to other resources, note-taking capability (saved to each registered trainee's personal space), assessments, and references. An optional pre-assessment and postassessment for the site's overall training allows the user to determine his or her learning progress.

Options for individual learning or group learning are built into Project ENABLE's training. An instructor or library director can register a group or class and monitor the progress of participants throughout the training. Several Library and Information Science (LIS) pre-service librarian preparation programs have used Project ENABLE as part or all of a graduate-level course or program and librarian trainer and library directors have used it to support face-toface training or for professional development credits. In addition, the site has a freely accessible database containing more than 1,000 searchable items and a blog addressing timely issues and authored by disabilities experts, library practitioners, and others.

When invited to partner with the Illinois State Library (ISL) and Dominican University on the Targeting Autism proposal to IMLS in 2015, the Project ENABLE team realized that, for the first time, it had the opportunity to turn its attention to developing online training on a specific disability, autism. While ISL and Dominican were devoting their efforts and resources to providing face-to-face forums, workshops, and coaching to Illinois librarians, Project ENABLE focused on providing an online, self-paced version of the training, within Project ENABLE, that could be used to support and as follow-up to the face-to-face training, as well as offering borderless and extended access to the training to librarians everywhere.

The International Journal of Information, Diversity, \& Inclusion, 3(4), 2019

ISSN 2574-3430, jps.library.utoronto.ca/index.php/ijidi/index

DOI: $10.33137 /$ ijidi.v3i4.32998 
The online learning module on autism that was developed in Project ENABLE, "Targeting Autism in Libraries," was intended to replicate and represent as much as possible of the content covered in the face-to-face training. But the advantages of online learning (e.g., flexible learning time, unlimited use of content) also allowed the Project ENABLE team to build on and expand the amount and depth of content far beyond what is possible in the Targeting Autism face-to-face learning, while also including extra support and interactive content (e.g., videos, exercises).

In addition, online training offered instant access to thousands of relevant online resources for trainees who wished to learn more about a topic of interest. It also provided the opportunity for the Targeting Autism project to potentially reach thousands more librarians worldwide.

As the training design began, it became clear, almost immediately, that this module would be significantly different than the other five modules in Project ENABLE. While following the general format of the other modules, the autism module required the inclusion of so much content that it needed to be broken up into six topics. These topics, some of which were as comprehensive as full Project ENABLE modules, were

- What is Autism?

- Diagnosis and Characteristics of Autism;

- Creating an Autism-Friendly Library;

- Autism-Friendly Library and Information programs, Services and Resources;

- Partnering with the Greater Community to Support Children and Adults with Autism; and

- Library Support and Opportunities: Employment of People on the Spectrum.

While other sections of Project ENABLE have one brief learning assessment at the end of each module, the autism module has a brief quiz at the end of each topic (a total of six quizzes in the autism module) and a module quiz specifically for trainees who wished to only participate in the autism training. Questions also were added to the overall Project ENABLE pre- and postassessments for trainees who decide to tackle all six of its learning modules. All scores are automatically saved to the trainee's personal space.

\section{Current Status}

The popularity of the annual forums led to the Illinois State Library's decision to fund a 2019 Targeting Autism Forum, held in River Forest, IL at Dominican University. A major focus of this year's forum was Autism and Civil/Human Rights. This topic addressed the urgency of what it means to be inclusive in an increasingly neurodiverse world. Autistic self-advocates spoke of the limitations of the medical model, which serves to focus on changing people rather than affirming their autism as an identity that encompasses individual learning styles and talents. Further, accommodations for behavioral and sensory challenges, while necessary, are not synonymous with inclusion.

The International Journal of Information, Diversity, \& Inclusion, 3(4), 2019

ISSN 2574-3430, jps.library.utoronto.ca/index.php/ijidi/index

DOI: $10.33137 /$ ijidi.v3i4.32998 


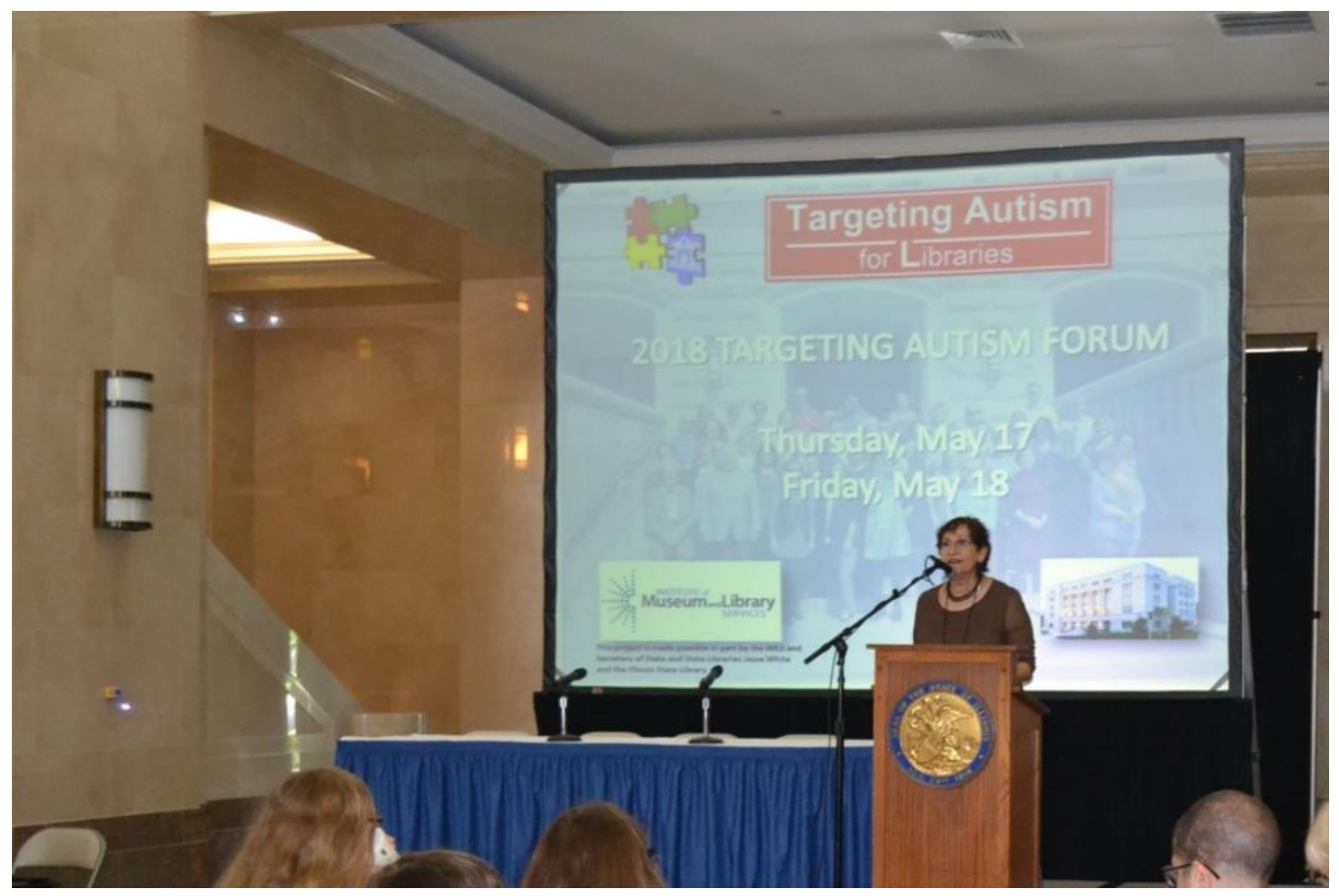

Figure 3. Suzanne Schriar, Illinois State Library and Director of Targeting Autism, welcomes attendees to the 2018 Targeting Autism forum.

Forum participants learned of the need for neurodiversity libraries and library collections to: (a) curate and provide access to a collection of information, materials, and resources on autism acceptance and neurodiversity; (b) amplify autistic voices; (c) reflect the goals of the neurodiversity movement and paradigm, as well as, the larger disability rights and disability justice movements; (d) fight stigma, ableism, oppression, and inaccessibility; (e) celebrate autistic culture \& autistic pride; and (f) promote inclusive schools and communities.

The "Targeting Autism in Libraries" module in Project ENABLE continues to be improved and enhanced. To date, 540 new librarians have registered to participate in the autism training module in Project ENABLE in the year since the module was launched. The Syracuse team, in partnership with Infopeople, was recently awarded a fourth IMLS grant to add new, unique opportunities for individual librarians who are seeking ways to educate themselves in library services to patrons with disabilities and for library directors who wish to provide in-house disabilities training to their staff.

\section{The Future}

Training efforts provided by professional organizations and consortia (e.g., American Library Association, Infopeople), by individual libraries and systems, and by efforts like the ones described above have put a dent into the need for training in the area of libraries and disabilities. But the need is still great and there is evidence that one-time training may not be enough for many trainees to feel competent and confident. Continual revision and enhancement of existing training, new ways to market alternative, multiple training options,

The International Journal of Information, Diversity, \& Inclusion, 3(4), 2019

ISSN 2574-3430, jps.library.utoronto.ca/index.php/ijidi/index

DOI: $10.33137 /$ ijidi.v3i4.32998 
reinforcement of learning through a range of methods, programs and activities, and providing a selection of customizable train-the-trainer resources to support individual libraries and library systems that wish to develop and offer their own, in-house training for their staffs are some potential ways of addressing that need.

Finally, the ubiquity of autism throughout the world coupled with global access to information, training, and networking via interactive social sites has challenged the Targeting Autism team to extend the geographic scope and universal relevancy of its autism education efforts. To date, the Targeting Autism blog has been viewed in 109 countries. All forum presentations have been recorded and are freely available online via the blog (https://targetingautismlibs.com/) and the Targeting Autism YouTube channel.

People impacted by autism from Canada, Trinity College in Dublin, and as far as the Volta Region of Ghana, to name just a few, have reached out with questions for the team. In addition, past forums have included a variety of international presenters from countries such as France, Trinidad and Ghana, as well as speakers describing current barriers present in diverse religious and ethnic communities, including African American, Latinx/Hispanic, and Muslim populations. Attendees have learned about unique and shared cultural stigmas, misconceptions, and stereotypes about autism.

Increasingly, the demands of our global community require that the implementation and dissemination of an autism education model be applicable and freely accessible throughout the world. Toward that end, we will continue to promote the global reach of autism education and provide support to libraries and library users regardless of where they reside.

\section{Acknowledgements}

Targeting Autism and Project ENABLE were funded in part by grants from the Institute of Museum and Library Services.

\section{References}

Brault, M.W. (2012, July). Americans With Disabilities: 2010, Household Economic Studies, Report Number P70-131, United States Census Bureau. https://www2.census.gov/library/publications/2012/demo/p70-131.pdf

Centers for Disease Control and Prevention (2018). Data \& statistics on autism spectrum disorder. Retrieved from https://www.cdc.gov/ncbddd/autism/data.html

Nelson, P. P. (1996). Library services for people with disabilities: Results of a survey. Bulletin of the Medical Library Association, 84(3), 397-401.

Small, R.V., Myhill, W. N., \& Herring-Harrington, L. (2015). Developing accessible libraries and inclusive librarians: An update and examples from practice. In B. Wentz, P.T. Jaeger, \& J. C. Bertot, (Eds.), Accessibility for persons with disabilities and the inclusive future

The International Journal of Information, Diversity, \& Inclusion, 3(4), 2019

ISSN 2574-3430, jps. library.utoronto.ca/index.php/ijidi/index

DOI: $10.33137 /$ ijidi.v3i4.32998 
of libraries (pp. 73-88). London, UK: Emerald.

Small, R. V., Snyder, J., \& Parker, K. (2009). The impact of New York's school libraries on student achievement and motivation: Phase I. School Library Research, 12, 1-29.

Sparrow, M. (2018, February 26). Why is the autistic unemployment rate so high? Retrieved from http: / / www.thinkingautismguide.com/2018/02/why-is-autistic-unemploymentrate-so.html

Ruth V. Small (drruth@syr.edu) is Laura J. \& L. Douglas Meredith Professor Emerita and Research Professor at the School of Information Studies (iSchool) at Syracuse University. Dr. Small's research focuses on the motivational underpinnings of human behavior in information contexts. Her work has earned her the 2001 Carroll Preston Baber Research Award from the American Library Association and the 1997 Highsmith Innovative Research Award from the America Association of School Librarians. She has authored or co-authored over 100 publications, including eight books. Ruth was co-editor of School Library Research and currently serves on the editorial board of The International Journal on Information, Diversity and Inclusion. She has been $\mathrm{PI}$ or co-PI on more than 30 grant-funded projects (including serving as PI on Targeting Autism), awarded by a variety of federal government agencies and foundations. Ruth has also received five teaching awards, including the Meredith Professorship, Syracuse University's highest teaching honor.

Suzanne Schriar (SSchriar@ILSOS.GOV) is the Associate Director of Library Automation \& Technology at the Illinois State Library. She has also served as the Principal Investigator on the IMLS funded National Leadership Grant, Targeting Autism: A National Forum on Serving Library Patrons on the Spectrum and on the IMLS Laura Bush 21st Century Librarian Grant, Targeting Autism: A Comprehensive Training and Education Program for Librarian. With support from the Illinois State Library and the Secretary of State and State Librarian, Jesse White, Suzanne is instrumental in planning the annual Targeting Autism Forum for librarians, service providers and autism advocates.

Mary Pelich Kelly (mary.pelich33@gmail.com) is Statewide Coordinator of The Autism Program of Illinois and serves as President of the Board of Directors of Autism Support of Central Illinois and Secretary of the Board of Directors of The Arc of Illinois. In her role as lead trainer for the Targeting Autism project, she provided training, consultation, and individual coaching to librarians on developing and implementing services and programs for patrons with autism.

The International Journal of Information, Diversity, \& Inclusion, 3(4), 2019

ISSN 2574-3430, jps. library.utoronto.ca/index.php/ijidi/index

DOI: $10.33137 /$ ijidi.v3i4.32998 